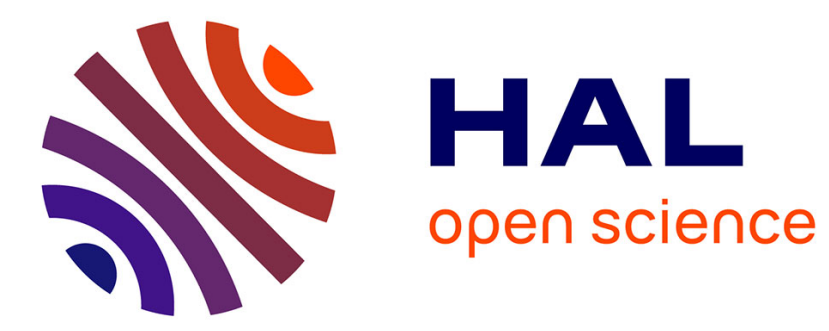

\title{
Straight wedge absorber geometry optimization for normal and oblique incidence
}

Laura Pometcu, Ala Sharaiha, Ratiba Benzerga, Philippe Pouliguen

\section{To cite this version:}

Laura Pometcu, Ala Sharaiha, Ratiba Benzerga, Philippe Pouliguen. Straight wedge absorber geometry optimization for normal and oblique incidence. Loughborough Antenna and Propagation conference, Nov 2014, Loughborough, United Kingdom. pp.633 - 636, 10.1109/LAPC.2014.6996472 . hal-01104332

\section{HAL Id: hal-01104332 \\ https://hal.science/hal-01104332}

Submitted on 16 Jan 2015

HAL is a multi-disciplinary open access archive for the deposit and dissemination of scientific research documents, whether they are published or not. The documents may come from teaching and research institutions in France or abroad, or from public or private research centers.
L'archive ouverte pluridisciplinaire HAL, est destinée au dépôt et à la diffusion de documents scientifiques de niveau recherche, publiés ou non, émanant des établissements d'enseignement et de recherche français ou étrangers, des laboratoires publics ou privés. 


\section{Straight Wedge Absorber Geometry Optimization for Normal and Oblique Incidence}

\author{
Laura Pometcu, Ala Sharaiha, Ratiba Benzerga \\ Institute of Electronics and Telecommunications of Rennes \\ University of Rennes 1 \\ Rennes, France \\ laura.pometcu@univ-rennes1.fr
}

\begin{abstract}
This paper presents a topology for improving the performance of straight wedge absorbing materials at oblique angles of incidence. The optimization process is based on a genetic algorithm and allows one to obtain a low reflection coefficient within a wide band of frequencies. We investigate the performance by comparison between the straight wedge absorber and the optimized wedge absorber. These wedge absorbers were simulated in the CST Microwaves Studio software, using a polymer foam material.
\end{abstract}

Keywords - straight wedge absorber; polymer foam; anechoic chamber; optimization algorithm; normal incidence; oblique incidence

\section{INTRODUCTION}

Microwave absorbers are one of the main components in anechoic chambers [1], used to eliminate reflected microwave signals. They are important elements for evaluation of many military and civil electronic systems. The straight wedge absorber shown in Fig. 1 is one of the shapes that are commonly employed as radio frequency absorbers giving good results at low frequencies [2]. In this study, an optimized topology of the wedge absorber is proposed and performances are compared for different angles of incidence, $0^{\circ}-45^{\circ}$ depending on how the incident electric field falls on the wedge. We use a polymer foam material with the electromagnetic parameters given in this paper. The optimization has been done for the $1-6 \mathrm{GHz}$ frequency range.

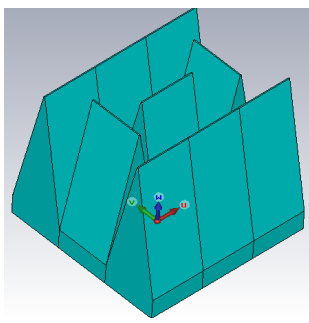

(a)

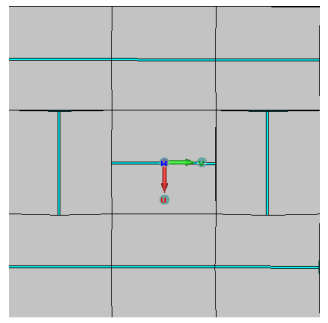

(b)

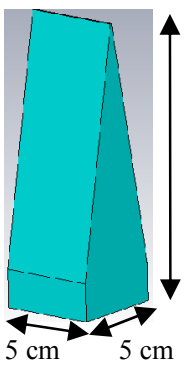

$15 \mathrm{~cm}$
Fig. 1. Straight wedge absorber. (a) Side view, (b) Front view.

\author{
Philippe Pouliguen \\ DGA/DS - Office for advanced research and innovation \\ Bagneux, France
}

II. THEORY

\section{A. Absorber material}

The polymer foam is an in-house material that has never been used before in microwave absorption applications. The first tests for the polymer foam loaded with carbon fibers $(0.6 \%$ by weight) are very encouraging. It has an attenuation of $41 \mathrm{~dB}$ at $10 \mathrm{GHz}$. This attenuation is comparable with the usual absorbent materials. In Fig. 2 and Fig. 3, the measured characteristics, permittivity and the loss tangent respectively, of this loaded polymer foam are presented.

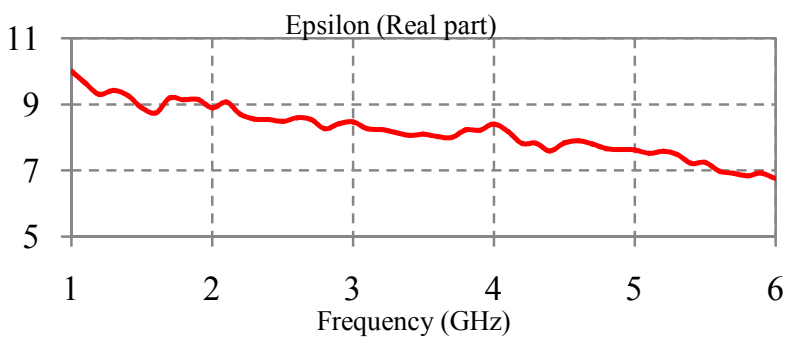

Fig. 2. Relative permittivity of the foam.

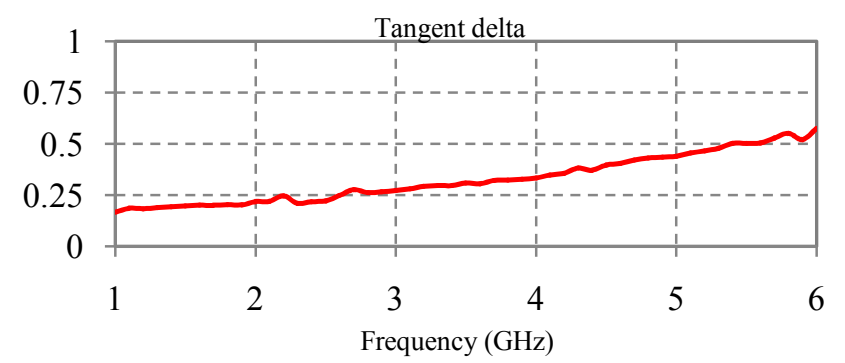

Fig. 3. Loss tangent of the foam.

We can note that for the frequency range $1 \mathrm{GHz}$ to 6 $\mathrm{GHz}$, the permittivity is varying from 6.5 to 10 and the loss tangent is increasing from 0.16 to 0.57 . 


\section{B. Genetic algorithm}

The genetic algorithm was primarily introduced in the 1970s by John Holland at the University of Michigan, United States. This algorithm works very well for combinatorial problems but it uses a lot of computer power [3].

It always needs a solution, a result to the problem at hand commonly called a genome or chromosome. In this case, the solution to the problem is the reflection coefficient. It has to be as low as possible. After defining the solution, the setting of the parameters is done. Here, because the wedge shape is being divided in equal parts, for each part the radius of the top and bottom square is set as a parameter for the optimization algorithm. These parameters will be used to calculate at each step the reflection coefficient until it reaches the optimum value.

\section{OPTIMIZATION AND SIMULATION RESULTS}

We consider the straight wedge absorber shown in Fig. 1. The overall dimensions are $15 \mathrm{~cm} \times 15 \mathrm{~cm} \times 15 \mathrm{~cm}$ and the base thickness is equal to $2 \mathrm{~cm}$. We divide the wedges in 5 equal parts plus the base [4]. Each layer has the same material characteristics. Their width and thickness as well as the thickness of the base are optimized. The optimization is carried out using the Genetic Algorithm optimizer in CST Microwave Studio. The determined optimum gives the lowest reflectivity at normal and oblique incidence.

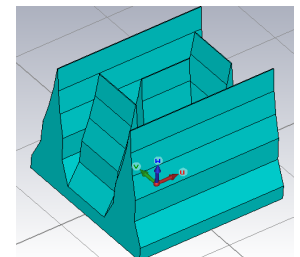

(a)

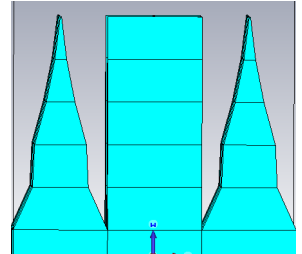

(b)
Fig. 4. Optimized geometry. (a) Side view, (b) Front view.

The optimized shape giving us the best performances is shown in Fig. 4. Its volume is equal to $1490 \mathrm{~cm}^{3}$ whereas the volume of the original shape is equal to $1942 \mathrm{~cm}^{3}$. There is a $24 \%$ less material.

\section{A. Normal incidence}

In Fig.5 and Fig. 6, we present a comparison between the original straight wedge geometry and the optimized one. We note that depending on the polarization the reflection coefficient at normal incidence has decreased by $5 \mathrm{~dB}$, in the frequency range $1-6 \mathrm{GHz}$, for the optimized straight wedge.

We have two cases: the first one is to assume that the incident electric field is polarized in the y-direction and in the second case the incident electric field is polarized in the $\mathrm{x}$-direction as it is shown in Fig. 5.

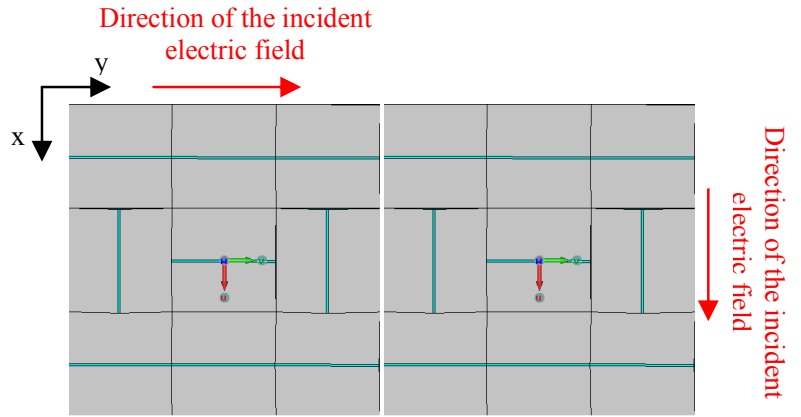

(a)

(b)

Fig. 5. Polarization of the incident electric field. (a) First case, (b) Second case.

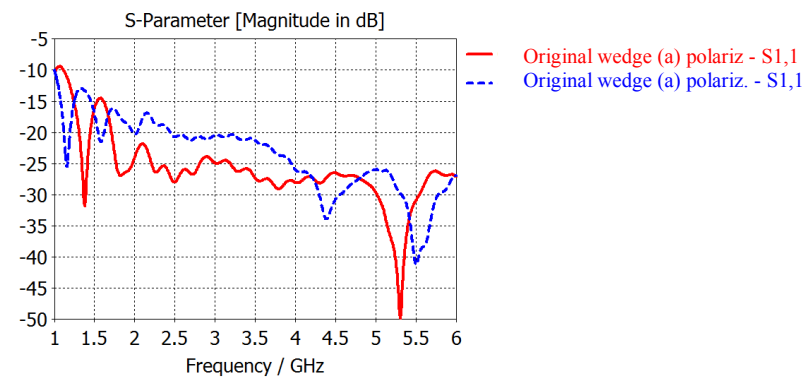

Fig. 6. Reflection coefficient in $\mathrm{dB}$ versus frequency at normal incidence.

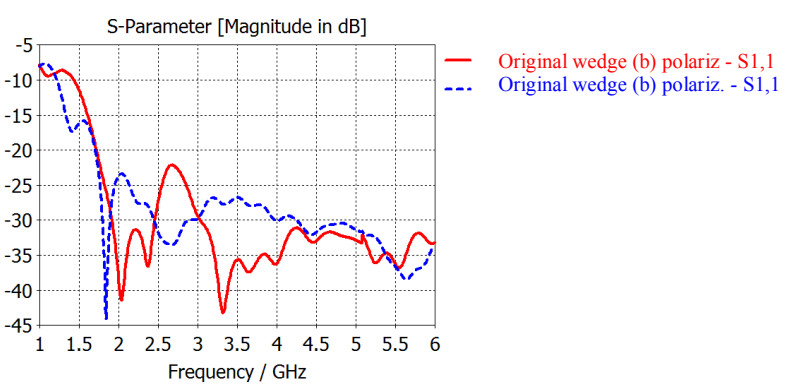

Fig. 7. Reflection coefficient in $\mathrm{dB}$ versus frequency at normal incidence.

When the incident electric field is in the x-direction then it interacts more with the material resulting into a higher reflectivity and a lower transmission. For case (b) when the incident electric field is in the $\mathrm{x}$-direction the transmission is higher and the reflectivity lower. We want to have a low reflectivity so we need to arrange the wedges in a manner that satisfies this condition. This is why most of the shapes are arranged perpendicular with the x-direction. In order to cover better the entire area some of the wedges are oriented differently. This ensures a better performance. We have an example in Fig. 8 where all the wedges are oriented in the same direction in comparison with our arrangement.

In Fig. 8 we have two resonant frequencies at $4.3 \mathrm{GHz}$ and $5.6 \mathrm{GHz}$ where the reflectivity is lower for the wedges oriented in the same direction but for the overall bandwidth our arrangement has a gain of 3 to $10 \mathrm{~dB}$ depending on frequency. 


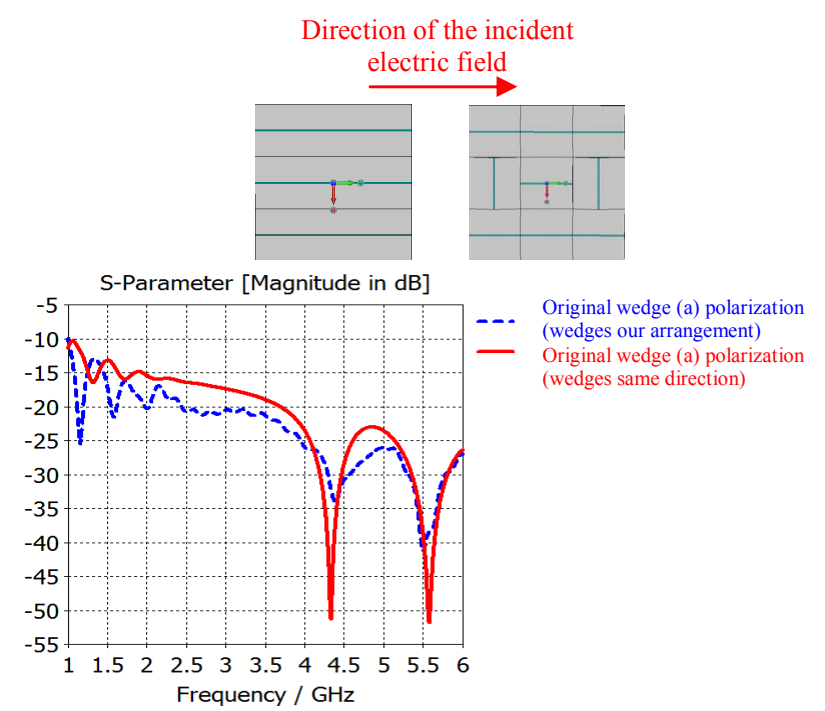

Fig. 8. Reflection coefficient in $\mathrm{dB}$ versus frequency at normal incidence for different wedge arrangements.

\section{B. Oblique incidence}

For oblique incidence only the $30^{\circ}$ and $45^{\circ}$ angles have been studied. Using these 2 angles the wave has been rotated around the geometry between $0^{\circ}$ and $360^{\circ}$ because of the asymmetry of the shape. We can note from Fig. 10 to Fig. 13, for the two cases that there is an improvement in performance for the optimized shape by approximately $21 \%$.

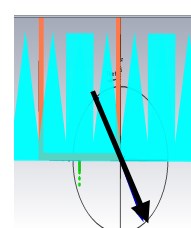

(a) (b)

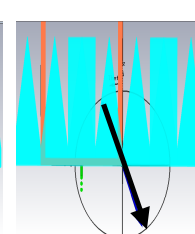

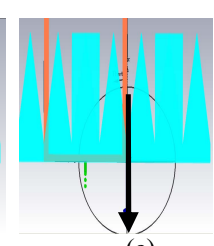

(c)

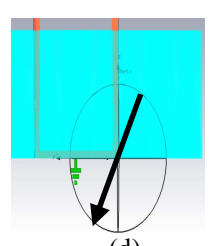

(d)
Fig. 9. Rotation of the oblique incidence wave around the asymmetrical geometry (a) $0^{\circ}$, (b) $30^{\circ}$, (c) $90^{\circ}$, (d) $360^{\circ}$.

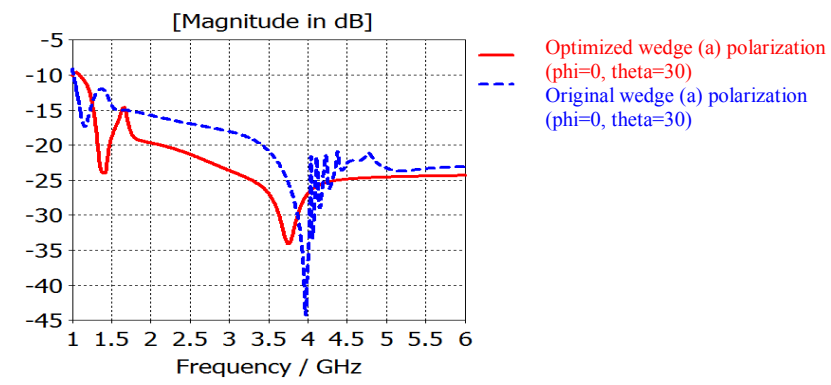

Fig. 10. Reflection coefficient in $\mathrm{dB}$ versus frequency at theta $=30^{\circ}$.

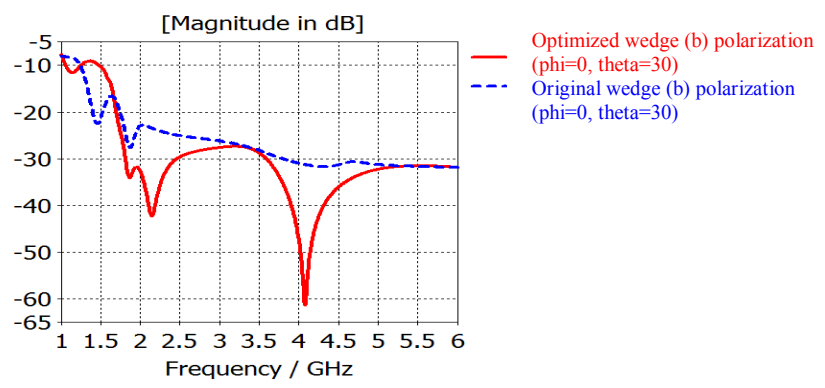

Fig. 11. Reflection coefficient in $\mathrm{dB}$ versus frequency at theta $=30^{\circ}$.

At oblique incidence with theta $=30^{\circ}$, the optimized wedge for case (a) has a mean reflection coefficient of approximately $-22 \mathrm{~dB}$ but for case (b) the mean value is -30 $\mathrm{dB}$ so the obsevation made at normal incidence that the incident electric field has to be perpendicular with the wedge in order to have lower reflectivity is demonstrated here also. The same thing is observed for theta $=45^{\circ}$.

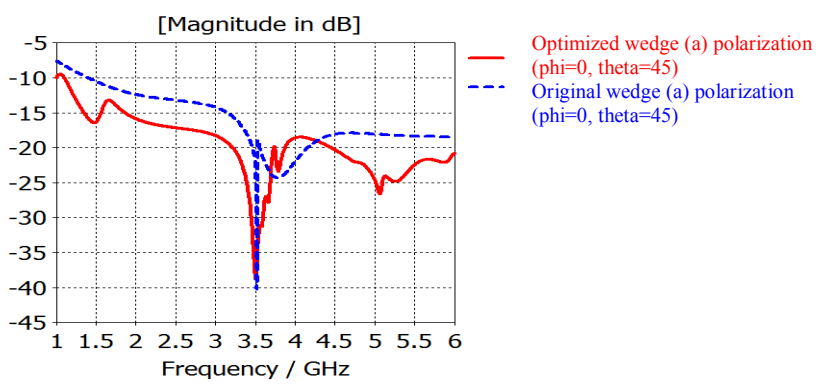

Fig. 12. Reflection coefficient in $\mathrm{dB}$ versus frequency at theta $=45^{0}$.

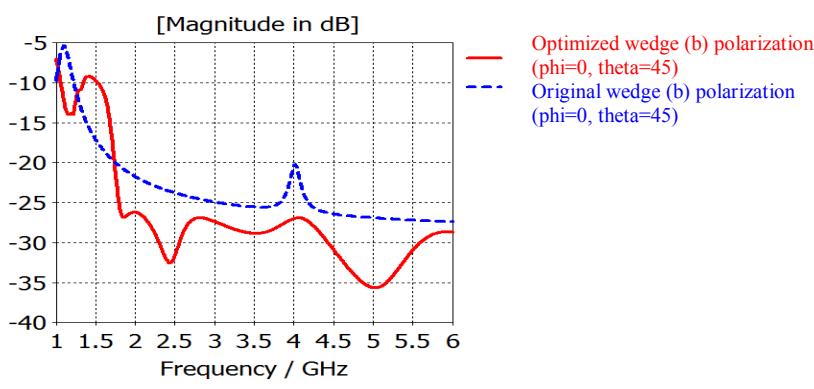

Fig. 13. Reflection coefficient in $\mathrm{dB}$ versus frequency at theta $=45^{\circ}$.

In Fig. 14 and Fig. 15., we give a 2D presentation of the reflection coefficient versus the frequency and the angle phi varying from 0 to 360 degrees around the absorbers, for different values of the incident angle theta. 


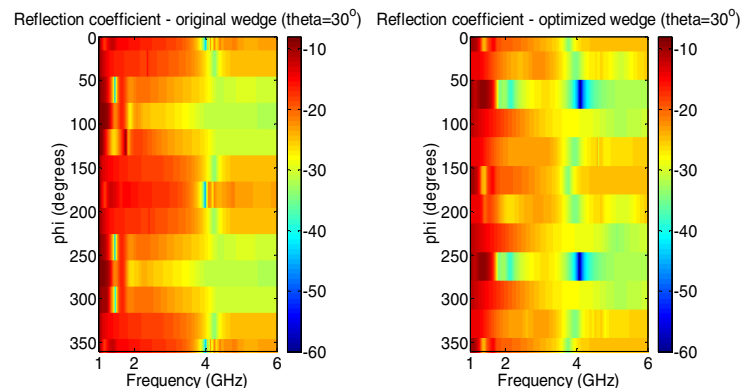

Fig. 14. Reflection coefficient in $\mathrm{dB}$ versus frequency at theta $=30^{\circ}$ depending on phi.

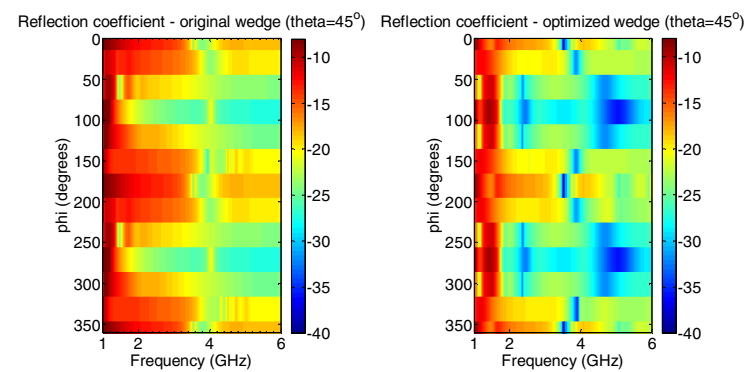

Fig. 15. Reflection coefficient in $\mathrm{dB}$ versus frequency at theta $=45^{\circ}$ depending on phi.

From Fig 14 and Fig. 15 can be deduced that for the optimized structure the return loss is lower (dark blue) especially at higher frequencies, between 3 and $6 \mathrm{GHz}$.

If we change the angle of incidence the reflection coefficient increases by $20 \mathrm{~dB}$ but still conserves a better performance for the optimized structure. This can be also observed in Fig. 16 and Fig. 17 where we show the reflection coefficient results at only one frequency, at oblique incidence, depending on the rotation of the wave around the structure which is given by phi $=0^{\circ}-360^{\circ}$.

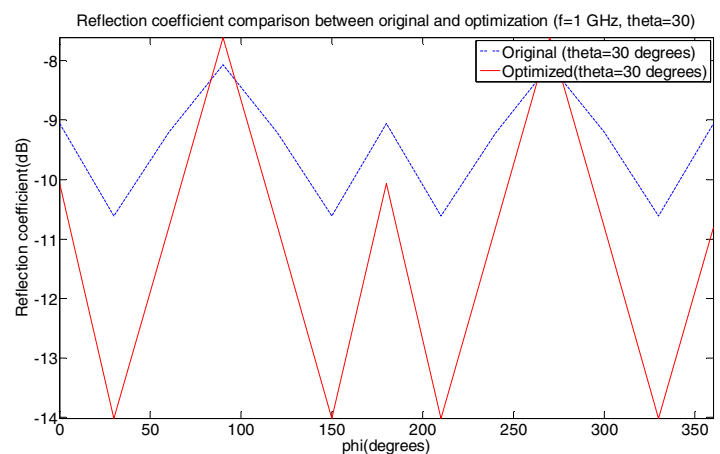

Fig. 16. Reflection coefficient in $\mathrm{dB}$ versus phi at theta $=30^{\circ}$ and the frequency $1 \mathrm{GHz}$, case (a).

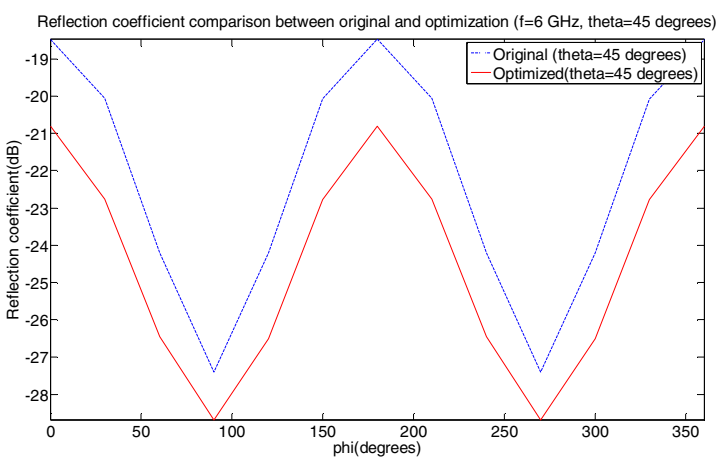

Fig. 17. Reflection coefficient in $\mathrm{dB}$ versus phi at theta $=45^{\circ}$ and the frequency $1 \mathrm{GHz}$, case (a).

\section{Comparison with commercial absorber}

In Table I the dimensions for our material and for a commercial absorber are shown. We have chosen a smaller size in order to use less material. Usually, the base size is 61 x $61 \mathrm{~cm}$. We defined the length of one wedge with $\mathrm{L}$, the width with $\mathrm{W}$, the thickness of base with $\mathrm{H}_{\mathrm{b}}$, the height of the wedge with $\mathrm{H}_{\mathrm{w}}$, the total height with $\mathrm{T}$ and the nominal weight with $\mathrm{M}$.

TABLE I.

\begin{tabular}{|l|c|c|c|c|c|c|}
\hline \multirow{2}{*}{ Material } & \multicolumn{5}{|c|}{ Dimensions (cm) } & $\begin{array}{c}\text { M } \\
\text { (kg) }\end{array}$ \\
\cline { 2 - 6 } & $\boldsymbol{L}$ & $\boldsymbol{W}$ & $\boldsymbol{H}_{\boldsymbol{b}}$ & $\boldsymbol{H}_{\boldsymbol{w}}$ & $\boldsymbol{T}$ & 2.62 \\
\hline $\begin{array}{l}\text { Polymer foam } \\
\text { original } \\
\text { wedge }\end{array}$ & 5 & 5 & 2 & 13 & 15 & 2.01 \\
\hline $\begin{array}{l}\text { Polymer foam } \\
\text { optimized } \\
\text { wedge }\end{array}$ & 5 & 5 & 1.5 & 12.32 & 13.83 & 1.9 \\
\hline $\begin{array}{l}\text { ECCOSORB } \\
\text { WG-4, wedge }\end{array}$ & 6.8 & 6.8 & 4.4 & 8.3 & 12.7 & \\
\hline
\end{tabular}

There is clearly less material used for the optimized wedge, a decrease by $610 \mathrm{~g}$. Using this new shape even if the density of our material is bigger than the one for polyurethane we obtain a good value for the weight, comparable with ECCOSORB WG-4 [5].

Table II shows the reflection coefficient results at normal incidence for our material and for a commercial material from Emerson \& Cuming [6].

TABLE II.

\begin{tabular}{|l|c|c|c|c|c|c|}
\hline & \multicolumn{6}{|c|}{ Reflection coefficient (dB) - Normal incidence } \\
\hline \multicolumn{1}{|c|}{ Frequency (GHz) } & $\mathbf{1}$ & $\mathbf{2}$ & $\mathbf{3}$ & $\mathbf{4}$ & $\mathbf{5}$ & $\mathbf{6}$ \\
\hline $\begin{array}{l}\text { Polymer foam original } \\
\text { wedge, case (a) }\end{array}$ & -9 & -20 & -20 & -26 & -26 & -26 \\
\hline $\begin{array}{l}\text { Polymer foam original } \\
\text { wedge, case (b) }\end{array}$ & -7 & -23 & -29 & -30 & -31 & -33 \\
\hline $\begin{array}{l}\text { Polymer foam } \\
\text { optimized wedge, (a) }\end{array}$ & -10 & -24 & -25 & -28 & -30 & -27 \\
\hline $\begin{array}{l}\text { Polymer foam } \\
\text { optimized wedge, (b) }\end{array}$ & -8 & -38 & -29 & -36 & -33 & -33 \\
\hline $\begin{array}{l}\text { ECCOSORB } \\
\text { WG-4, wedge }\end{array}$ & -18 & -23 & -39 & -32 & -38 & -35 \\
\hline
\end{tabular}


The chosen commercial material from Emerson \& Cuming, ECCOSORB WG-4, has the same geometry as our material, that is straight wedge. With the optimized geometry, case (a), at normal incidence, we obtain the minimum of $-10 \mathrm{~dB}$ at $1 \mathrm{GHz}$ that is required for a material to be considered a good absorber. Our material has a low percentage of carbon. Even like this the results that are obtained are closer to the commercial material for the optimum and not for the original wedge. At some frequencies the polymer foam has even comparable results at normal incidence.

If the original wedge would have been used we would have had lower absorption and higher reflection and the performance would have decreased by $9.5 \%$.

\section{CONCLUSIONS}

We have proposed a new shape of wedge absorber giving better performance with a smaller size at normal incidence and oblique incidence. This optimized straight wedge geometry can be used efficiently to reduce the reflection in an anechoic chamber.

\section{ACKNOWLEDGMENT}

The authors would like to thank the Direction Générale de l'Armement (DGA), France for its financial support.

\section{REFERENCES}

[1] L. H. Hemming, Electromagnetic Anechoic Chambers: A Fundamental Design and Specification Guide, 2002, Chapter 3.

[2] H. Nornikman, P. J. Soh, F. Malek, A. A. H. Azremi, F. H. Wee, R. B. Ahmad, "Microwave wedge absorber design using Rice Husk - An evaluation on Placement Variation", IEEE, Perlis, Malaysia, 2010.

[3] www.lancet.mit.edu/mbwall/presentations/IntroToGAs/

[4] S. Kent and I. Catalkaya, " Optimized geometry pyramidal absorber for normal incidence case", IEEE, Istanbul, Turkey, 2013.

[5] www.ecanechoicchambers.com/TB/EB-115\%20-\%20WG-NRL.pdf

[6] http://www.eccosorb.com/products-eccosorb-high-loss-absorbers.htm 